\title{
SOBRE EL INDIGENISMO DE CESAR VALLEJO
}

\author{
POR \\ PHYLLIS RODRIGUEZ-PERALTA \\ Temple University, Philadelphia
}

E1 elemento más valioso y distintivo de la literatura peruana ha sido siempre lo indígena, lo indio. Una sensación de la presencia indígena ha permeado todos los aspectos de la literatura, tomando diferentes formas de acuerdo con los momentos históricos y el desarrollo de la expresión literaria.

Después de la primera guerra mundial, un cambio significativo de valores y perspectivas comenzó a incorporarse a la gradual pérdida del monopolio de Lima en la cultura e influencia tradicionales. En la década de los años veinte, un gran número de intelectuales peruanos centró su atención en la vasta masa indígena del interior del país. Al mismo tiempo, el tenue trato literario dado antes a las misteriosas regiones y poblaciones andinas se convirtió en indigenismo literario, una de las más vigorosas corrientes en la literatura peruana. Enfocado en un majestuoso ambiente andino de grandeza y desolación, y en los habitantes de este primitivo y aislado mundo, el indigenismo peruano evolucionó de la fase de descripción externa de ámbitos geográficos y humanos hasta penetrar parcialmente la realidad indígena. Protestas por la explotación e injusticias sufridas por el indio andino constituyen el núcleo de esta literatura.

El punto de partida de un actual período de indigenismo regional en el Perú lo marca la publicación de Cuentos andinos, de Enrique López Albújar, en 1920; pero la literatura indigenista peruana no quedó definida inmediatamente. Durante la década de 1920 a 1930, la literatura referente al indio peruano fue a menudo ambivalente en su apreciación. Cuentos andinos, por ejemplo, presenta una imagen mal enfocada de la raza con énfasis en personajes criminales y patológicos ${ }^{1}$. Otros autores de la

${ }^{1}$ López Albújar nació en la ciudad de Piura, situada en la zona costeña. Se puso en contacto con los indios cuando fue enviado como juez a la región andina. 
década se concentraron más en el material documental que literario. Otros, que desconocían el ambiente andino, continuaron con el concepto del indio como una criatura exótica.

El indigenismo peruano alcanzó su madurez en la década de los treinta $^{2}$. La trilogía de Ciro Alegría, La serpiente de oro (1935), Los perros hambrientos (1938) y El mundo es ancho y ajeno (1941), contenía todas las facetas de la década previa, y trajo al Perú la culminación de una corriente literaria que estaba ya declinando en muchos países latinoamericanos. José María Arguedas, que comenzó como un escritor indigenista tradicional en Agua (1935) y Yawar fiesta (1941), más tarde sobrepasó las limitaciones conceptuales y técnicas del indigenismo. Su novela Todas las sangres (1964), vasto trabajo sociológico, excede el formato indigenista y solamente retiene un esquema del molde original. Intentos de integrar al indio en la vida nacional, y de ver en él una futura fuerza política o económica, evolucionaron en una reevaluación de su propia cultura y herencia.

César Vallejo pertenece a la corriente indigenista en la literatura peruana, aun cuando su aportación indigenista forma solamente una parte pequeña de sus extraordinarias contribuciones literarias. Un provinciano nacido en el pueblo andino de Santiago de Chuco, Vallejo llegó con todos sus inherentes atributos indígenas a la cosmopolita costa. En Lima, en 1918, publicó Los heraldos negros, en donde expone la magra existencia del pueblo serrano, una existencia acerca de la cual los nativistas posteriores solamente podrían especular, un ambiente que confundiría al costeño al experimentarlo por primera vez.

En su visión desolada de la vida serrana, Vallejo se compenetra y simpatiza con la tristeza del indio, con el sentido de su pérdida y abandono. En esta temprana etapa, las emociones de la derrota y la degradación son las que preocupan al poeta:

En los paisajes de Mansiche labra imperiales nostalgias el crepúsculo; y lábrase la raza en mi palabra, como estrella de sangre a flor de músculo.

2 Raimundo Lazo, discutiendo el concepto de «lo andino» y la abundante narrativa literaria que pertenece a esta categoría, estima más de cuatro mil obras de todos los géneros o especies literarias dentro de la literatura indigenista peruana del siglo xx. La novela andina (México: Porrúa, 1971), p. 13. 
Un poyo con tres patas, es retablo en que acaban de alzar labios en coro la eucaristía de una dicha de oro.

\section{II}

La anciana pensativa, cual relieve de un bloque pre-incaico, hila que hila; en sus dedos de Mama el huso leve, la lana gris de su vejez trasquila.

Hay ficus que meditan, melenudos trovadores incaicos en derrota, la rancia pena de esta cruz idiota.

En la hora de rubor que ya se escapa, y que es lago que suelda espejos rudos donde náufrago llora Manco-Cápac.

\section{III}

Como viejos curacas van los bueyes camino de Trujillo, meditando. $\mathrm{Y}$ al hierro de la tarde, fingen reyes que por muertos dominios van llorando.

$\mathrm{La}$ aldea, ante su paso, se reviste de un rudo gris, en que mugir de vaca se aceita en sueño y emoción de huaca.

Y en el festín del cielo azul yodado gime en el cáliz de la esquila triste un viejo coraquenque desterrado.

\section{IV}

La grama mustia, recogida, escueta ahoga no sé qué protesta ignota;

La niebla hila una venda al cerro lila que en ensueños miliarios se enmuralla, como un huaco gigante que vigila.

(Porciones de los cuatro sonetos de «Nostalgias imperiales») 
En la aldea de las afueras de Trujillo, Vallejo siente una emanación de tristeza, una sensación de vacío y silencio que reflejan la vasta melancolía de la región andina que él siempre lleva dentro de sí. Este es el mundo indio como Vallejo lo veía, el cual asume con todos los remordimientos de una raza conquistada. El hecho de que Vallejo use conceptos modernistas para crear sensaciones de tristeza no niega la profundidad de su sentir ni la veracidad de las sensaciones. En la estrofa que comienza «Un poyo...», la mezcla de vocablos regionales y modernistas es como la mezcla de lo indio con lo español. La «cruz idiota» que los españoles trajeron a los indios es también la cruz que los descendientes están soportando en su presente estado de derrota.

En Los heraldos negros, el indigenismo regional de Vallejo fluye tan naturalmente como las palabras quechuas y locales que aparecen con frecuencia. «Emoción de huaca», en una de las líneas arriba — sinónimo de «emoción de muerte»- cambia el tono del español a peruano. Esta esencia peruana continúa en expresiones locales de la sierra, en los recuerdos personales de una niñez serrana, en las vistas y los sonidos de un aislado pueblo, y en la presencia del indio. El sabor andino -nada familiar para el limeño- colocaba a Vallejo a la vanguardia del fermento indigenista peruano.

Aunque una conciencia india emana de su poesía, Vallejo no es el indio que se expresa a sí mismo. Más bien, el poeta está presente en la poesía con el indio, mirándole «saboreando el romance peruano de tu coca» («Los arrieros»), escuchando «la triste voz de un indio dondonea / como un viejo esquilón de camposanto» («Aldeana»), comprendiendo su frustración: «Es fiesta... Echa una cana al aire el indio triste... El ojo del crepúsculo desiste / de ver quemado vivo el caserío» («Terceto autóctono»). (En esta transposición de sentimientos, aun la naturaleza refleja el odio de los indios hacia sus opresores.) Muchas veces, como en «Oración del camino», Vallejo incorpora su propia amargura, con la pérdida de identidad y esperanza del pueblo conquistado: «Ni sé para quién es esta amargura... ¿Oyes? Regaña una guitarra. ¡Calla! / Es tu raza, la pobre viejecita / que al saber que eres huésped y que te odian, / se hinca la faz con una roncha lila... la aurífera canción de la alondra que se pudre en mi corazón.» En el abandonado y relegado estado del indio, Vallejo siente su propia orfandad y aislamiento, y la existencia humana sin significado. $\mathrm{Y}$ responde con preguntas amargas y con compasión.

En la dualidad de su naturaleza, Vallejo refleja a menudo actitudes indias de nostalgia mística, tristeza subjetiva, resignación, un sentido de fatalidad. El poeta, claramente enterado de su mestizaje, se identifica como el desorientado y desarraigado producto del choque de dos culturas: 
Soy el pichón de cóndor desplumado

por latino arcabuz;

y a flor de humanidad floto en los Andes

como un perenne Lázaro de luz.

(«Huaco»)

Los limeños contemporáneos de Vallejo no pudieron captar las implicaciones de su mestizaje. Para ellos, el serrano Vallejo, tan extraño en concepto y expresión, era simplemente el indio Vallejo. El hecho de que él era un mestizo perteneciente a una tradicional familia católica (como la gran mayoría de sus detractores costeños) y que pertenecía a la clase media andina, sin los mismos problemas que los indios segregados, no significaba nada para ellos. (El cholo Vallejo, que no entra en el molde limeño, representa la indianización del serrano a la que Arguedas se refería con énfasis años más tarde.) El rechazo del pueblo indio y la carencia de un lugar digno en la escena nacional se repite en el desprecio y el rechazo de Vallejo en Lima. El indigenismo inherente en la temprana poesía de Vallejo ${ }^{3}$, con su textura telúrica serrana, era inaceptable para el costeño. Lima no tenía ojos para ver ya sea la cualidad personal de la poesía o la incorporación de Vallejo mismo en el sufrimiento humano de la vasta población aislada que habitaba la región andina.

El mismo desinterés mereció la prosa de Vallejo publicada en 1923, en vísperas de su partida para Francia. Sin embargo, su prosa -particularmente en un estudio sobre el indigenismo de Vallejo- constituye un segmento importante de su obra, aun cuando la estatura del prosista no iguala a la del poeta. Sus trabajos de prosa creativa no son muy numerosos, y por lo menos la mitad de ellos no fueron publicados durante la vida del autor. A pesar de esto, la mayoría de su prosa coincide muy de cerca con el desarrollo de los aspectos del indigenismo literario, en contraste con su poesía, que tomó una dirección alejándose de lo andino. Ahora que las fechas de su obra han sido establecidas - y generalmente aceptadas-, un estudio cronológico de su prosa muestra una gradual combinación de indigenismo regional y protesta social. La dicotomía entre poeta y prosista se ensancha mientras él progresa. La poesía, de intensa angustia universal, es subjetiva; la prosa, medida y exploratoria, es objetiva.

${ }^{3}$ Los límites de este estudio no permiten un comentario de Trilce (1922). En esta colección, las notas regionales son devoradas en la libre asociación de las figuras. En vez de un sentido del indio hay un sentido del alma de la región andina, como en los versos: «solloza la sierra de mi alma» (LIV), "Andes frío, inhumanable, puro» (LIX), y otros más efímeros e interiores. Su mestizaje específico está también cubierto de la misma manera. 
Para presentar la situación del indio - y la del serrano-, Vallejo, en Fabla salvaje (1923), se aparta de la cualidad personal de su poesía y adopta la narración impersonal del típico escritor indigenista. Objetivamente, él relata el desarrollo de esquizofrenia paranoide en un joven esposo andino que termina en tragedia. A través de toda la historia, Vallejo muestra su familiaridad con los trastornos pseudopsicopáticos relacionados con los cambios fisiológicos asociados a la altitud. La tensión aumenta, mientras Balta pierde el sentido de la realidad, hasta la culminación, cuando se arroja de un precipicio tratando de evitar a alguien que imagina le roza por la espalda.

Balta Espinar nunca es identificado como indio. El es un ser humano, «con su viril dulcedumbre andina... Era agricultor. Era un buen campesino, más de la mitad oscuro aldeano de las campiñas» ${ }^{4}$. Como Alegría más tarde en El mundo es ancho y ajeno (1941), Vallejo se sitúa frente al paisaje andino para describir e interpretar al protagonista andino. Nos dice que Balta es rústico y fuerte, que quizá él no es muy inteligente, pero que tiene gran sentido común:

... un buen animal racional, cuyas sienes situarían linderos, esperanzas y temores a la sola luz de un instinto cabestreado con mayor o menor eficacia, por ancestrales injertos de raza y de costumbres. Era bárbaro, mas no suspicaz (p. 106).

En Fabla salvaje se puede percibir la presencia del ambiente andino a través del vocabulario local (poyo, chacra, yaraví, jalcas peruanas, zonzo, papaseca) y las costumbres y supersticiones que están entretejidas en la historia. No se percibe la intención de aproximar las formas morfológicas y fonológicas del idioma local, y ocasionalmente un diálogo local sigue la disparatada construcción en la sintaxis de un campesino: «Para que muera mi madre una mañana, muchos días antes de la desgracia, cantó una gallina vieja, color de habas, que teníamos» (p. 197).

La descripción de la región andina es sostenida y constante, pero ni lírica ni agobiante. El lector no está tan consciente de los altos picos y de los lujuriantes valles andinos como lo es de la primitiva existencia de Balta y de sus crecientes problemas psicológicos. La descripción más poética ocurre justamente antes de la tragedia final; ésta es la única vez en que Balta y la naturaleza convergen:

${ }^{4}$ César Vallejo, Obras completas, tomo 2 (Barcelona: Editorial Laia, 1976), pp. 96-97. Todas las citas de Fabla salvaje, Escalas melografiadas, Hacia el reino de los Sciris y Cuentos son tomadas de esta misma edición. 
Balta, sentado en el filo de la roca, miraba todo esto como en una pintura... Contempló largamente el campo, el límpido cielo turquí, y experimentó un leve airecillo de gracia consoladora, y un vasto candor vegetal. Abríase su pecho en un gran desahogo y se sintió en paz y en olvido de todo, penetrado de un infinito espasmo de santidad primitiva (p. 129).

Aspectos del indigenismo literario entran oblicuamente en partes de la colección Escalas melografiadas (1923). El escenario andino puede percibirse en el color de las cosechas, en la rústica construcción de las casas serranas, en la presencia de «una anciana de bohío» —nunca identificada como «india»- Un viaje lleva al autor a través de la cordillera y los valles calientes, y cruza el gran río Marañón, pero estos hechos no van acompañados con descripciones objetivas ni subjetivas.

«Los caynas», de la misma colección, presenta otra historia de demencia andina donde el protagonista, y toda la villa de Cayna, se creen monos. En la que es quizá la primera narrativa peruana de protesta social, Cayna es identificada como un solitario y aislado pueblo andino que, «separado de los grandes focos civilizados del país por inmensas y casi inaccesibles cordilleras, vivía a menudo largos períodos de olvido y de absoluta incomunicación con las demás ciudades del Perú» (p. 63). El sarcástico retrato que Vallejo hace de los efectos del aislamiento y abandono en los habitantes de este primitivo mundo no pudo haber pasado por alto en la frívola y presuntuosa capital. El sarcasmo es culminado por el final hurgonazo de Vallejo apuntando que los caynas están convencidos de que el de fuera es loco: «iPobre! Se cree hombre. Está loco» (p. 69).

Fabla salvaje y las pocas notas de Escalas constituyen las únicas contribuciones en prosa al desarrollo de la literatura indigenista durante el tiempo que Vallejo vivió en el Perú. Aunque éstas no son de ninguna manera definitivas, demuestran claramente que aun en esta temprana etapa el enfoque central de Vallejo está en lo sociológico más que en lo emocional. Sus personajes no están creados para provocar lazos sentimentales en sus lectores. La insistencia en las cualidades primitivas de Balta excluye las dulzonas observaciones que Ciro Alegría hace del indio y el orgullo de su identidad cultural en Arguedas. Además, Vallejo se refiere al serrano en general más que al indio en sí. Esto lo diferencia de López Albújar, quien coloca al indio en una categoría humana separada. Sin embargo, el tono de la prosa indigenista de Vallejo en 1923 es muy similar al de Cuentos andinos, particularmente en la proporción entre la descripción de los paisajes andinos y la acción de la historia. Asimismo, la insistencia de Vallejo en aberraciones mentales a menudo resulta en la misma imagen de primitivismo como la que presenta López Albújar. 
En París, durante los años 1924-1928, Vallejo entra en el pasado peruano con su novela corta indianista Hacia el reino de los Sciris ${ }^{5}$. A primera vista, esta imaginaria reconstrucción del mundo incaico parece un desvío inesperado en la trayectoria literaria de Vallejo. Como parte de una búsqueda por una identidad americana, ciertamente fue instigada por doctrinas políticas contemporáneas que pusieron énfasis en las originales culturas y civilizaciones americanas ${ }^{6}$. Quizá sea de más importancia el hecho de que esta novela corta muestra la concomitante influencia de otros escritores peruanos que miraban al pasado incaico con un sentido de belleza y fascinación.

Un dorado concepto de una civilización antigua, construido cuidadosamente a través del romanticismo y del modernismo, se combinaba muy bien con la literatura de orientación europea de los limeños que trataban de ignorar la presencia de la vasta población indígena en los Andes. Las complejidades de un modernista tradicional se reflejan en Abraham Valdelomar, quien tornó con naturalidad hacia sus escenas costeñas de toques regionales, pero simultáneamente fue al pasado incaico con una actitud puramente estética. La publicación póstuma de Valdelomar, Los hijos del sol (1921), influyó temporalmente en algunos escritores peruanos que conscientemente buscaban sumergirse en las imaginarias bellezas de la antigüedad nacional ${ }^{7}$.

De una manera tortuosa, estas escenas artísticas incaicas toman parte en el desarrollo del rumbo indigenista en el Perú. Clemente Palma, quien escribió el prólogo a Los hijos del sol, refleja los sentimientos ambivalentes de su generación hacia el indio. El confiesa que la civilización incaica nunca despertó su entusiasmo, y entre otras razones menciona la humildad de sus descendientes, su primitivismo, los piojos que siempre les acompaña, todo lo que le hacía dudar de la existencia de una mentalidad poética en el imperio incaico. Pero Palma añade que las bellas descripciones que hace Valdelomar del remoto pasado indio le han hechos revalorizar sus actitudes.

Vallejo, en Hacia el reino de los Sciris, trata de transmitir alguna realidad en la reconstrucción del pasado incaico. Hay negros grumos de historia en la sucesión de los incas, en el territorio que ellos conquistaron

${ }^{5}$ Publicación póstuma de 1944, en forma incompleta, en la revista Nuestro Tiempo (Lima), núms. 1, 2 y 3. Georgette de Vallejo dice que ella vio a Vallejo corregir el manuscrito original en 1932-33.

- Los nombres de González Prada, Mariátegui y Haya de la Torre, en el Perú, son los más prominentes en la discusión sobre la reivindicación del indio y su incorporación en la sociedad contemporánea.

${ }^{7}$ Por ejemplo, Augusto Aguirre Morales (El pueblo del sol, 1927). 
y en las descripciones del esfuerzo colectivo y el sacrificio rendidos para construir la fortaleza de Sajsahuamán con sus enormes bloques de roca en perfecta unión. La importancia para el imperio de constantes guerras y conquistas está puntualizada en el primer capítulo, propiamente intitulado «El otro imperialismo». Hay movimiento a través de toda esta novela corta, y por lo menos un intento de penetrar viejas costumbres y creencias quechuas, aunque sea solamente con la imaginación. A pesar de que palabras quechuas desconocidas son usadas en abundancia $-\mathrm{y}$ así incrementa el aire de exotismo-, la descripción misma es menos ornamentada que en comparable prosa peruana, y no está presente el énfasis modernista en lo sensual, ni los estilizados efectos de luz para intensificar el drama. Aun así, todo está impregnado de un sentido de artificialidad, además de que el trabajo de Vallejo no elude el terreno de lo fantástico.

Descartando abruptamente este intento de regresar a orígenes raciales, Vallejo escribió la novela El tungsteno (1931) como una obra indigenista de protesta social. Publicada el mismo año del ingreso de Vallejo al partido comunista, la novela refleja la influencia de sus viajes a Rusia, junto con sus experiencias como testigo presencial de las injusticias y represiones en el Perú ${ }^{8}$. Combinando elementos de una novela proletaria y una novela indigenista, se presenta aquí una mezcla de luchas de clases y divisiones raciales: el jerárquico sistema social andino, que, a su turno, refleja el choque de dos culturas. El tungsteno trata de la explotación de las masas indígenas por una inhumana compañía extranjera de minas, por autoridades peruanas corruptas y pervertidas y por un predominante desprecio hacia la raza nativa.

La novela está estructurada en tres partes. Las dos primeras tienen varias subdivisiones: la más corta, sección final, es la coronación resultante de las escenas descritas en las dos primeras secciones. El narrador, consistentemente omnisciente, no trata de entrar en el mundo indio. Siempre se mantiene la perspectiva exterior, a pesar de la simpatía por el sufrido indio, y no hay exhibición de actitudes paternalistas.

La sección I, que ocurre en el asiento minero de Quivilca, comienza con una descripción de la «vasta indiada» que inicialmente se vierte en la empresa norteamericana «Mining Society». Dólares pronto convierten la apacible vida provincial en un bullicioso alboroto. Los soras, indios primitivos que habitan en esta área, primero sirven a la empresa como guías

${ }^{8}$ En 1910 Vallejo trabajó en las oficinas mineras norteamericanas de Quiruvilca; en 1911 fue tutor del hijo de un rico hacendado y propietario de minas; en 1912, un ayudante de cajero en la hacienda Roma, vasta finca de caña de azúcar cerca de Trujillo. 
y luego inocentemente comienzan a rendir todo lo que poseen. Los obreros, aunque censuran el tratamiento que la compañía da a los soras, están muy listos a sacar ventajas de ellos. La mayoría los llama «indios brutos», «raza indébil, servil, humilde» ${ }^{9}$. La sección se cierra con una asquerosa escena donde todos los principales protagonistas, incluyendo al gerente y subgerente extranjeros, toman parte en la violación de Graciela, a quien han jugado al cacho. Entran en turno por «orden de jerarquía social y económica» (p. 183).

La sección II resume todo lo perverso de la sociedad peruana en las provincias. Los hermanos Marino, quienes se enriquecieron como agentes al servicio de la empresa norteamericana, son aliados del subprefecto en la pesquisa de conscriptos para el ejército, así como de trabajadores para la empresa. La patética captura de dos indios conscriptos es interrumpida por los comentarios del narrador acerca de la población india que vive «fuera del Estado peruano y fuera de la vida nacional» (p. 207). Los viciosos personajes de costumbre en la novela indígena —el juez (de Lima), el rico propietario, el cura, el subprefecto- ilustran una básica inhumanidad, que se refleja también en la crueldad de los gendarmes (la mayoría son costeños) y en la callosa insensibilidad de los vecinos de Colca. Servando Huanca, un herrero e indio puro, tiene el coraje de protestar contra la injusticia. Se produce una corta sublevación, que es despiadadamente sofocada por los gendarmes; luego, la pequeña burguesía de Colca culpa a los indios por el derramamiento de sangre. Tal clima de bajeza, naturalmente, prepara el camino al marxismo.

La sección III, nuevamente en Quivilca, se dedica enteramente a discusiones políticas entre Huanca y Leónidas Benites (agrimensor y anteriormente estudiante en la Escuela de Ingenieros en Lima). Huanca predice una revolución mundial en la que todos los explotadores serán derrocados y los «indios» de todas partes serán liberados. Aunque Benites inicialmente se aferra a su creencia de que son los intelectuales los que deberían gobernar $-\mathrm{y}$ él tiene dificultades en avizorar indios ignorantes en el gobierno-, está finalmente convencido de que los intelectuales deberían servir a la clase trabajadora bajo las órdenes de ésta. El viento que anuncia la tempestad y que termina la novela es una referencia obvia a la revolución que se aproxima.

El tungsteno sigue la fórmula general de la novela indigenista. Sobre todo condena las injusticias sufridas por los indios andinos. Rasgos familiares de la novela del indio están presentes en episodios comunes a este

9 César Vallejo, Novelas y cuentos completos (Lima: Moncloa, 1970), p. 159. Todas las citas de El tungsteno son tomadas de esta edición. 
género, en el énfasis puesto en el primitivismo psicológico y en una nota de profundo pesimismo. Pero Vallejo no reduce el acento descriptivo usual al detalle geográfico, ni presta mucha atención a las costumbres locales ni a las aproximaciones de modelos linguísticos. La rapidez de los sucesos y las narraciones condensadas impiden el desarrollo de protagonistas individuales; sin embargo, no hay esfuerzo por crear un tono panorámico o épico del indio-masa. La perspectiva no es la de un artista, sino la de un crítico social.

Lo que Vallejo agrega a esta novela es un intento de aplicar su nueva ideología al ambiente indígena andino y así poder ofrecer una solución a problemas propios de la injusticia social ${ }^{10}$. Mas esta solución marxista parece la simplificación de una situación compleja, principalmente porque su aplicación entre gente primitiva es presentada sólo teóricamente en las doce últimas páginas. Aunque Vallejo, deliberadamente, estructuró su novela de modo que culminara en esta discusión, un discurso unidimensional de ideas políticas y sociales no es muy convincente. Al separar este mensaje del resto de la novela, Vallejo ilustra parte de los límites conceptuales y técnicos del indigenismo literario. (Esta falta de integración continuará en los escritores indigenistas, incluyendo a Alegría, quien también expone explícitas ideas sociales y políticas en un capítulo separado al final de El mundo es ancho y ajeno.) Además, si la intención de Vallejo fue la de hacer de El tungsteno una novela proletaria, anti-imperialista, sólo obtuvo un éxito parcial. En esencia, esta novela retiene su carácter indigenista porque la condición del indio se superpone a los conflictos económicos y de clases. Vallejo escribió partiendo de un conocimiento personal de la explotación del indio por el feudalismo y el imperialismo, pero el intento de hacer de El tungsteno una obra que sirva de hito a un propósito político o sociológico debilita su impacto. El conocimiento de Vallejo acerca de la realidad social andina es inequívoco; y el sistema represivo de casta, las iniquidades sociales y económicas, los efectos del capital extranjero, todo aboga por la necesidad de un cambio radical. Desafortunadamente, las técnicas novelísticas que actúan según el esquema de la novela indigenista no son las más adecuadas para expresar la complejidad de esas situaciones.

Aunque El tungsteno fue una buena novela peruana de protesta social, tuvo roca influencia en la prosa que emergía en el Perú. En lugar de per-

${ }^{10}$ Roberto Paoli insiste que cuando Vallejo visitó Rusia «vio la sociedad soviética con ojos de indio: su espíritu del 'ayllu' agrícola se reproducía en una sociedad tecnológica moderna, pero racionalmente organizada como la de los Incas». «Observaciones sobre el indigenismo de César Vallejo», Revista Iberoamericana, XXXVI (abril-junio 1970), p. 343. 
seguir la ruta socioeconómica, el tratamiento del indio en la narrativa peruana procederá a través del lirismo de las novelas de Alegría y la progresiva interiorización de Arguedas. Sin embargo, El tungsteno no es obra que pueda ser dejada de lado en el desarrollo de la novela peruana, ya que muchos argumentos de esta obra de 1931 fueron retomados y ampliados años más tarde en novelas de mayor alcance como, por ejemplo, Todas las sangres (1964), de Arguedas.

«Paco Yunque», un cuento escrito e $\mathrm{n} 1931^{11}$, también es reminiscente de escenas en Todas las sangres. Colocado en una sala de clase, la disparidad de manera de trato acordada al humile sirvientito Paco Yunque y la acordada a Humberto Grieve (hijo del rico director de «Peruvian Corporation Railroads» y patrón de Paco Yunque) es materia suficiente para probar el tema social de Vallejo. La relación de victimador/víctima entre los dos niños, que sustituye la explotación del pobre por el rico, le interesa a Vallejo más que el hecho obvio (pero nunca mencionado) de que Paco es indio y Humberto blanco. Aunque demasiado sentimental, el cuento es mucho más efectivo en transmitir su mensaje que el explícitamente doctrinario El tungsteno.

La mujer andina en las obras de Vallejo ocupa la posición tradicional reservada para ella en toda la literatura indigenista. Ella hace el hogar; conforta, obedece, rinde completa confidencia a su varón; es madre, pura, amorosa, industriosa, paciente, abnegada, silenciosa. (Adelaida, la mujer de Balta, siente un respeto casi religioso por su marido.) En escenas domésticas, la mujer andina es siempre la compañera ayudante, la que sufre más y la que nunca ocupa un centro de importancia. En escenas generales, ella se encuentra en el fondo, como apoyo no más para la acción principal. Solamente una vez es tomada en consideración en su papel, en Fabla salvaje, donde un pequeño cree que su hermana debe sentirse como una esclava en indoblegable yugo. La dulzura femenina que pertenece a la raza alcanza también a las relaciones entre madre e hijo, que aparecen en todas las referencias que Vallejo hace de su propia madre y en los confortantes pensamientos de Paco Yunque acerca de la protección materna. En un papel opuesto está la mujer que existe para el placer del hombre. Generalmente seducida a una temprana edad, esta mujer pasa de dueño a dueño cosechando desdenes y abusos. Laura, en El tungsteno, se ocupa en múltiples trabajos: de cocinera, lavandera, sirvienta y, además, querida de los dos hermanos Marino. El narrador comenta que ella ha adquirido el "gusto del pecado». Mujeres de alto nivel social no se

${ }^{11}$ Publicado póstumamente en 1951 en Apuntes del Hombre (Lima), núm. 1. La publicación de este cuento fue rechazada en España en 1931. 
ven. Hombres de este nivel aparecen en relaciones que reflejan el status de patrón-sirvienta. Según la fórmula general de trabajo indigenista, los protagonistas masculinos siempre ocupan el espacio central de la novela y la acción se desarrolla enteramente alrededor de ellos. La mujer es enfocada fuera del módulo principal de poder e importancia y nunca permitiendo que ella actúe por sí misma frente a cualquier evento, el énfasis se pone en la insignificancia de su rol familiar y social ${ }^{12}$.

Vallejo, ocasionalmente, toca el tema de la posición de la Iglesia en la sierra peruana. El cura de El tungsteno forma parte integral de los explotadores y los aventaja en hipocresía. Es el cura quien ofrece un brindis a los norteamericanos, cuyo dinero «hace agacharse al obispo». Vallejo admite los sentimientos religiosos de los indios, pero critica su superstición y la falta de entendimiento que, en su opinión, han resultado de la carencia de una educación adecuada. Censura la pretensión, el orgullo falso y la insensibilidad de los católicos, cuyas virtudes cristianas nunca son puestas en práctica. La extraña visión que Leónidas Benites tiene del Sagrado Corazón y la hora del Juicio (durante el delirio de una alta fiebre) está a múltiples interpretaciones ${ }^{13}$. El tormento de Benites no viene tanto de la pérdida del Paraíso como de la expresión de infinita tristeza reflejada en el rostro de Jesús. Y como un pecador perdido, él se lamenta de no haber llevado una vida cristiana. Quizás Vallejo quería que la lista de pecados sirviera de una admonición para los sinceros cristianos. Como quiera que sea, es el descolorido e ineficaz Benites quien al final acepta las doctrinas políticas marxistas de Huanca.

E1 año 1931 marca la cumbre de la prosa indigenista y de protesta social de Vallejo. Para entonces sus ideas de una sociedad socialista incluían algunos aspectos de la comunidad indígena con su énfasis colectivista (ideas que se encuentran en algunos poemas de la misma época en los cuales el indio de espíritu colectivista se une con el obrero bolchevique $\left.{ }^{14}\right)$. Las obras en prosa que siguen a El tungsteno y "Paco Yunque» retornan a su esencia local pertrana.

${ }^{12}$ La poesía de Vallejo refleja el mismo papel generalmente dado a la mujer: es la figura venerada de la madre, la mujer como instrumento sexual, y la sumisa mujer andina. «¿Qué estará haciendo a esta hora mi andina y dulce Rita de junco y capulí?»

${ }^{13}$ La escena está basada en el cuento «Sabiduría», el cual fue publicado en Amauta (1929) como un «capítulo de una novela inédita». Jean Franco cree que las modificaciones hechas para su incorporación a El tungsteno demuestran un reconocimiento del conflicto entre la doctrina cristiana y la sociedad capitalista. César Vallejo. The Dialectics of Poetry and Silence (London: Cambridge Univ., 1976), p. 157.

${ }_{14} \mathrm{Tal}$ como «Los mineros salieron de la mina» $\mathrm{y}$ «Gleba». Georgette declara que estos poemas y otros que evocan al Perú («Telúrica y magnética», «Fue domingo 
Cuatro cuentos de menor importancia corresponden a los años 19351936 , según Georgette de Vallejo ${ }^{15}$. «El niño del carrizo» y «El vencedor», relatos puramente regionales en carácter, diseñan escenas de la infancia de Vallejo en un pueblo andino de provincia. Una vez más, Vallejo evita divisiones raciales en favor de distinciones sociales en la sierra. En una riña en el patio del colegio entre «el niño pobre» y «el niño decente», las simpatías de todos los niños van del uno al otro, y al final todos están tristes, aun el vencedor.

El irónico «Viaje alrededor del porvenir» se refiere a los esfuerzos de un administrador para engendrar un hijo en su esposa porque el patrón le ha prometido diez mil soles. Aunque el concepto de raza está implícito en la estructura social, la atención de Vallejo se dirige al rígido sistema de clases usado en la hacienda. En orden descendente está el desdén del patrón hacia su administrador, el engaño del administrador a los trabajadores y el anonimato de éstos. La arrogancia típica de la figura del gamonal en la literatura indigenista es exhibida por este patrón en el «español chinesco» que él usa para todos los que son económicamente inferiores a él. En su niñez, los obreros en la hacienda de su padre habían sido chinos, tratados como esclavos. Para el patrón no tiene ninguna importancia el hecho de que en lugar de los coolies ahora son indios quienes le sirven. Además de censurar la inhumanidad de tal situación, Vallejo hace notar la ignorancia de estos provincianos.

En «Los dos soras», Vallejo separa e identifica «el indio» en los dos protagonistas, Juncio y Analquer, «de la tribu de los soras». Cuando ellos entran en una aldea la gente les grita: «QQué indios tan estúpidos! Parecen animales... Son salvajes... Son dos brujos. Son descendientes de los incas» (p. 189). La lección moral es amarga. Cuando los indios ignorantes ríen de gozo en la iglesia durante solemnes ceremonias religiosas, son expulsados del templo y encarcelados por su blasfemia. Vallejo termina aquí con su historia, pero su condenación es obvia. ¿Quiénes los mantuvieron salvajes y sin asistencia en sus apuros? ¿Quiénes los hicieron salvajes para castigarlos más tarde por su abyecto estado?

Casi incidentalmente dos piezas teatrales de incierto valor literario dieron el toque final al trabajo de Vallejo. La primera, una farsa satírica

en las claras orejas de mi burro», etc.) fueron concebidos durante su viaje a Rusia en 1931. César Vallejo, Obra poética completa. «Apuntes biográficos sobre 'Poemas en prosa y poemas humanos'» (Lima: Moncloa, 1968), p. 494.

${ }_{15}$ Publicados por primera vez en Novelas y cuentos completos (Lima: Moncloa, 1967 [primera edición]). «Los dos soras» había aparecido solo, el mismo año, en Amarú, núm 1 (enero). Las citas en el texto son de la edición Laia, de 1976, citada en nota 4. 
llamada «Colacho Hermanos o Presidentes de América», fue escrita en 1933, pero Vallejo no consiguió ponerla en escena ${ }^{16}$. Una rama de $E l$ tungsteno, los caracteres y las escenas iniciales, son fácilmente identificables como procedentes de la novela original, a pesar de algunos cambios en los nombres. Se repite el gringo gerente de la "Quivilca Corporation» que llama a los soras «indios brutos», «raza inferior, podrida» (p. 35). El resto de la farsa deja la sierra peruana y sigue a uno de los hermanos Colacho a Lima y a la presidencia. Este rápido e increíble «ascenso» proporciona a Vallejo abundantes razones para ridiculizar la ignorancia y el egotismo de la democracia burguesa del Perú. La otra pieza, «La piedra cansada» (Georgette dice que fue escrita después de los poemas de Espa$\tilde{n} a$, aparta de mí ese cáliz ${ }^{17}$ ), es una prolongación de Hacia el reino de los Sciris. Muchos efectos estilizados y una atmósfera llena de misterio y superstición aumentan la artificialidad. Esta fantasía es interferida, sólo una vez, por ideas que han estado creciendo durante más de diez años que separan este drama de la novela corta: en un breve diálogo, varios quechuas discuten si es posible, en el orden social, que el pueblo pueda estar por encima del Inca, de la nobleza y del clero. Ninguna de las dos piezas teatrales resulta en dramas cohesivos, ni tampoco dan sugerencias de cómo solucionar los conflictos. Sin embargo, la revisión del material andino demuestra la continua preocupación de Vallejo por los problemas políticos y sociales del Perú.

La universalidad de César Vallejo no puede ignorar que él fue también un escritor indigenista. Su trabajo indigenista comenzó con poesía que emanaba de sus propias experiencias personales, de sus propias impresiones del ambiente andino. Desde que estuvo ligado a la tierra peruana por estrechos lazos familiares y emocionales, Vallejo no separó el pueblo indio del pueblo serrano. Más tarde, desde París, su prosa comenzó a referirse a la población india como una entidad, a estudiar su situación desde diferentes ángulos, para luego sugerir alguna solución. En esta trayectoria Vallejo se une a la evolución literaria del indigenismo peruano, anticipado por él con un sentido de peruanismo genuino en su poesía y ahondado en su novela de protesta social.

${ }^{16}$ Una nota antes de la pieza menciona la estrecha relación del drama con una serie de artículos que Vallejo publicó en Germinal, de París, en 1933, con el título «¿Qué pasa en el Perú?». Vallejo escribió un esbozo de guión cinematográfico con la misma temática de «Colacho hermanos», que no se conserva. Teatro completo, tomo 2 (Lima: Universidad Católica del Perú, 1979), p. 11.

${ }^{17}$ En su nota de introducción a "La piedra cansada», Georgette critica severamente el texto de este drama publicado en 1969 por el Instituto Nacional de Cultura. Según ella, la versión no fue autorizada y resultó completamente incorrecta. Teatro completo, p. 148. 
En un mundo de desequilibrio, injusticias y contradicciones económicas, la prosa de Vallejo pone énfasis en la necesidad de revaluar y cambiar la realidad socioeconómica del indio. En su poesía, la figura del indio queda unida, en un abrazo fraterno, a todos los que sufren. La ansiedad de Vallejo por las esperanzas de cambios sociales, aún no cumplidos en el Perú, existe lado a lado con su angustia por el destino universal del hombre.

Quizás no sea necesario separar el indigenismo de Vallejo de la totalidad de su trabajo. Sin embargo, es una medida de él, como hombre que en su universalidad nunca perdió su visión de lo indígena:

¡Oh campos humanos!

¡Oh campo intelectual de cordillera,

¡Sierra de mi Perú, Perú del mundo, y Perú al pie del orbe; yo me adhiero!

¡Indio después del hombre y antes de él!

iLo entiendo todo en dos flautas

y me doy a entender en una quena!

(De «Telúrica y magnética», en Poemas humanos) 